Periodica Polytechnica Chemical Engineering, 65(4), pp. 536-549, 2021

\title{
Failure Analysis of Heat Exchangers with a Valid CFD Simulation
}

\author{
Ádám Sass ${ }^{1}$, Alex Kummer² ${ }^{2 *}$ Zsolt Ulbert ${ }^{2}$, Attila Egedy² \\ 1 KALL Ingredients Ltd., H-5211 Tiszapüspöki, 1 Fehértó part, Hungary \\ 2 Department of Process Engineering, Faculty of Engineering, University of Pannonia, H-8200 Veszprém, 10 Egyetem Street, \\ Hungary \\ *Corresponding author, e-mail: kummera@fmt.uni-pannon.hu
}

Received: 27 August 2020, Accepted: 10 December 2020, Published online: 09 August 2021

\begin{abstract}
Energy efficiency, safety and stable operation of units are the most crucial aspects in every industrial process. In this study, Computational Fluid Dynamics (CFD) simulations were used to study heat transfer in a laboratory-sized tubular heat exchanger. A partly 2D axisymmetric and mainly 3D model of the heat exchanger was created and validated with several simulation in different operating points of heating capacity and volume flow. The results of the simulations were compared to experimental data to validate the model. The inlet and outlet temperatures were measured with Pt100 temperature probes, and the surface temperatures were measured with an infrared camera. The heat transfer coefficient was determined based on the surface measurements The validated model was applied for the investigation of performance losses of heat exchanger due to fouling caused by particle deposits along the tube which caused reduced heat transfer surface or performance and a failure of heating wire which caused reduced heating performance, hence altered heat and flow characteristics through the equipment. The results provide useful information not only in the design processes but the operational lifetime as well.
\end{abstract}

Keywords

computational fluid dynamics, infrared camera, fouling, heating wire failure, performance analysis, validation

\section{Introduction}

Heat exchangers are one of the most generally used equipment in the chemical industries. In most technologies, there is a general need to heating or cooling material streams to provide optimal temperature level for the chemical processes and reactions, phase and component separations, etc. The rate of heat transfer inside the heat exchanger can be significantly degraded due to fouling or any failure. Deposits can reduce the heat transfer surface, or they can form a layer resulting in worse heat transfer properties, or even change the flow characteristics inside the heat exchanger. Ocłon et al. [1] investigated the effect of fouling on the thermal performance, so they studied how the outlet flue gas temperature varies with different values of the thermal resistance. The results shows that the outlet temperature of flue gas could increase by $122 \mathrm{~K}$ due to the deposit inside the tube [1]. Han et al. [2] developed an integrated fouling model with a deposition and a removal process to simulate the fouling characteristics. This study presents that the fouling resistance increases with time and it approaches to a stable value. Suárez et al. [3] applied a similar deposit-removal rate model for the simulation of the fouling layer. Paz et al. [4] developed a framework to calculate a dynamic mesh model in Ansys Fluent to recreate the movement of the fouling-fluid interface. As a result they are able to show the fouling layer evolution at different time steps.

There are two approaches to predict the performance losses of heat exchangers. The traditional way is to use historical data and calculate a reliability measure, which can be used for future failure prediction. The other way is to use model-based calculations. In this case, the predictions can be made by using validated mathematical models based on a priori information. Computational Fluid Dynamics (CFD) modelling is an excellent way to model and evaluate heat exchangers. In this respect, the application of CFD tools are useful to obtain detailed information about the flow and heat transfer processes inside the heat exchanger. After specifying the geometry, selecting the appropriate model equations and defining an adequate 
computational grid, a reliable solution can be obtained in most cases [5]. CFD provides a cost effective alternative to investigate heat exchangers in detail [6]. After getting the solution, the sources of failures can be identified, and the exact reasons for performance losses can be calculated reliably. Ocłoń and Łopata [7] investigated the effect of fouling on the performance of a heat exchanger with CFD techniques, and they state that the fouling of heat exchanger tubes may lead in short period operation to a failure due to the significantly higher outlet temperatures.

In laminar flow, the pieces of the liquid flow in a straight line along the direction of the pipe and do not mix with other layers of fluid. In contrast to turbulent flow when fluid is moving chaotically and swirling around. When the flow characteristics are turbulent, the calculation of flow becomes more challenging. Multiple equations have been developed to make the flow field in turbulent domain possible to calculate. The most important turbulence models are RANS (Reynolds Averaged Navier Stokes), $k-\varepsilon, k-\omega$ models, and Spalart-Allmaras model [8, 9].

Aslam Bhutta et al. [10] calculated turbulence flow inside the heat exchanger. They conclude that $k-\varepsilon$ turbulent model can be advantageously used for both shell and tube, and tube in tube type heat exchangers. They showed that the simulation results obtained are in a good agreement with the measurement, but the pressure loss was mostly overcalculated (by $\pm 5-20 \%$ ). The same simulation model was used to predict the heat transfer coefficient. However, the accuracy proved to be lower with a difference between 5-36\%.

Rehman [11] presented a CFD simulation of a heat exchanger without baffles, so in that construction, the flow of cooling fluid was parallel to the tube wall. $k-\omega$ model was used with corrections for low Re number to calculate turbulent flow. The pressure loss and the heat transfer coefficient was overestimated by $20 \%$.

During modelling, different simplifications can be done; for example, the application of porous material models on the shell side or applying symmetry boundaries to reduce the computational time [11]. Ozden and Tari [9] used a smaller scale heat exchanger to predict the flow field inside an industrial size heat exchanger. The baffle size and distance were optimised to lower the recirculation rate. The $k-\varepsilon$ and the Sparalt-Allmaras models were applied with computational grids of different sizes. They found good agreement with measurement results only with a $2 \%$ difference in case of heat transfer coefficient.
Zeyninejad Movassag et al. [12] in 2013 presented a simulation study of an industrial size heat exchanger. Two different types of baffles were implemented, a segmented and a helical type. They found that the helical baffles have less flow-breaking effect than the segmented ones. Han et al. [13] in 2014 calculated the particle deposition on the outer surface of tubes in a shell and tube exchanger. Turbulent flow implementing the $k-\omega$ model was used in the calculation of the liquid phase while the inelastic collision model was applied for the calculation of the particle motion. They found that the deposition of the particles mostly occurs in dead zones, or where the flow redirects. The intensification of the flow will lead to higher heat transfer coefficient. However, the number of particles deposited will be higher as well due to the multiple collisions to the tubes [13]. Pan et al. [14] used commercial CFD software to calculate the heat transfer and pressure drop in helical rectangular heat exchangers. Based on the results, one of the heat exchangers was chosen based on the performance, and it was validated within a thermal-compressor system. Youssef et al. [15] investigated the effect of heat transfer fluid flow rates and inlet temperatures effect on the performance of heat exchangers with phase change material. The implemented detailed 3D model of the spiral-like device is an excellent tool to understand the processes taking place during the charge and discharge process of the phase changing heat exchanger, which could ensure optimal operation.

Reddy et al. [16] performed a CFD analysis of a tubein-tube helical coil heat exchanger. Different flow rates were tested, and the heat transfer processes were investigated. They got a difference between the simulated and the empirical heat transfer coefficients, which were lower than $10 \%$ in all cases. Somasekhar et al. [17] created a simulation model for a multi-pass shell and tube exchanger. Their primary goal was to test different heat transfer media by adding nanoparticles to the base fluid (distilled water). The effects of Pe number, volume concentration, and particle type was investigated on the pressure drop and heat transfer characteristics.

The CFD tools are useful for industrial purposes or factory applications. However, heat transfer modelling can be extended for waste heat recovery in buildings [18], Earth to Air heat exchangers [19], regenerative mini channel heat exchangers [20], or oscillatory flow exchangers [21]. The computational time increases with the number of mesh elements (so the improvement of the accuracy). 
Impractically large computational times can be reduced by parallel and GPU computing, or cloud computing which has some support for open source software as well.

One of our novelties is a new infrared thermometer-based validation method, where we used surface temperature measurements for the validation of the model. In our experimental and simulation study, a CFD simulation of a laboratory sized tubular exchanger and the validation of the model are presented. As a second novelty, we discuss in detail the steps of the CFD simulation development, where we present how the information gained from the 2D model can be transferred into a 3D model to increase the stability of computation and to decrease the computational time. The advantages and disadvantages of CFD simulators and different meshing techniques were also discussed. We applied the validated model to investigate different type of failures of heat exchangers in two case studies. In the first case we calculated the performance loss due to fouling, and in the other case we investigated the performance loss due to a heating wire failure. We investigated the fouling phenomenon with particle tracing method, where only the solution of the momentum balance is necessary to get results about the expected places of deposits. With this method critical information can be gained in less time compared to other techniques (like adaptive mesh calculation for the modelling of the fouling domain).

\section{Materials and methods}

A laboratory sized electrically heated tubular heat exchanger was investigated and presented in Fig. 1. The heat exchanger consists of six steel tubes connected through $90^{\circ}$ elbows using copper nuts. The tubes contain $4 \mathrm{~kW}$ internal heating wires, and the material of the heating wires is kanthal alloy with ceramic insulation and it is coated with a steel layer. The main dimensions of the heat exchanger are introduced in Table 1. A Honeywell Experion PKS Hybrid Control system is used for the control of the heat exchanger.

The water is fed in the lower part of the device through XV001 on/off valve, and its feed rate can be adjusted by a control valve (FV001). The flow measurement of the water was carried out with an ultrasonic flow meter (Flexim Fluxus F601, accuracy $\pm 1 \%$ ) which was set up on the outside surface of the pipe. The inlet and outlet temperature is measured by a Honeywell STT 3000 temperature transmitter with Pt100 resistance sensor $(0.01 \%$ or $0.1 \mathrm{~K}$ accuracy). Foundation Fieldbus connection is used for the
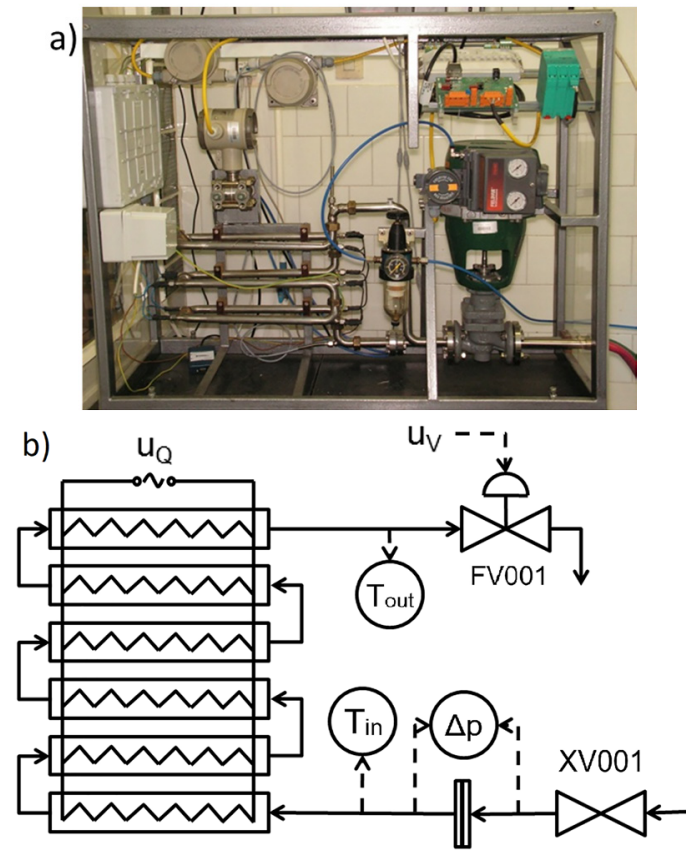

Fig. 1 a) Photo of the tubular heat exchanger; b) The schematic diagram of the equipment

Table 1 The dimensions of the heat exchanger

\begin{tabular}{lc}
\hline Dimension & Value \\
\hline Outer tube diameter $[\mathrm{mm}]$ & 21.5 \\
Inner tube diameter $[\mathrm{mm}]$ & 18.0 \\
Heating wire diameter $[\mathrm{mm}]$ & 1.5 \\
The thickness of the ceramic insulation $[\mathrm{mm}]$ & 2.0 \\
The thickness of the shell layer $[\mathrm{mm}]$ & 1.0 \\
Length of the tubes $[\mathrm{mm}]$ & 350 \\
Length of $90^{\circ}$ elbows $[\mathrm{mm}]$ & 75 \\
Inlet area $\left[\mathrm{mm}^{2}\right]$ & 245 \\
\hline
\end{tabular}

data transfer. Temperature measurements and the actuator position of the control valve can be recorded. The time constant of the temperature probes is negligible compared to the time constant of the system.

\section{Experiment results}

To develop a valid model and simulation of the presented laboratory equipment we performed some measurements. First, we defined the characteristic of the flow valve (FV001) presented in Subsection 3.1. We revealed the relation between the heating intensity and the outlet temperatures, and we measured the effect of the flow valve opening on the outlet temperatures (see Subsection 3.2). We performed measurements with infrared sensors to improve our simulation results (see Subsection 3.3). Appendix A shows all the measurement data for each experiment. 


\subsection{Characteristic of the flow valve (FV001)}

The correlation between the outlet flow rate and actuator position of the control valve is not linear; hence, we determined the characteristic of the valve. Fig. 2 shows how the flow rate varies with the valve actuator position. A third-degree polynomial equation was fitted to the data giving Eq. (1). It describes the relation between the valve position as $x$ and the outlet flow rate as $q_{v}(1 / \mathrm{h})$, which will be used to calculate the flowrate for the simulation.

$q_{v}=0.0002 x^{3}+0.0098 x^{2}+1.053 x+3.4451$

Table 2 shows some operation points of the control valve, where the flow rates and Reynolds numbers are introduced at different actuator positions $(25 \%, 50 \%$, $75 \%$ ).

Reynolds numbers were calculated to verify the application of the momentum balance equations. As the Reynolds numbers show, the flow is within the laminar regime in case of the 25 and $50 \%$ valve position, and the flow is within the transitional regime in case of $75 \%$ valve position. A low Re number $k-\varepsilon$ turbulence model for momentum balance modelling should be capable of providing adequate calculation for all the three operation points.

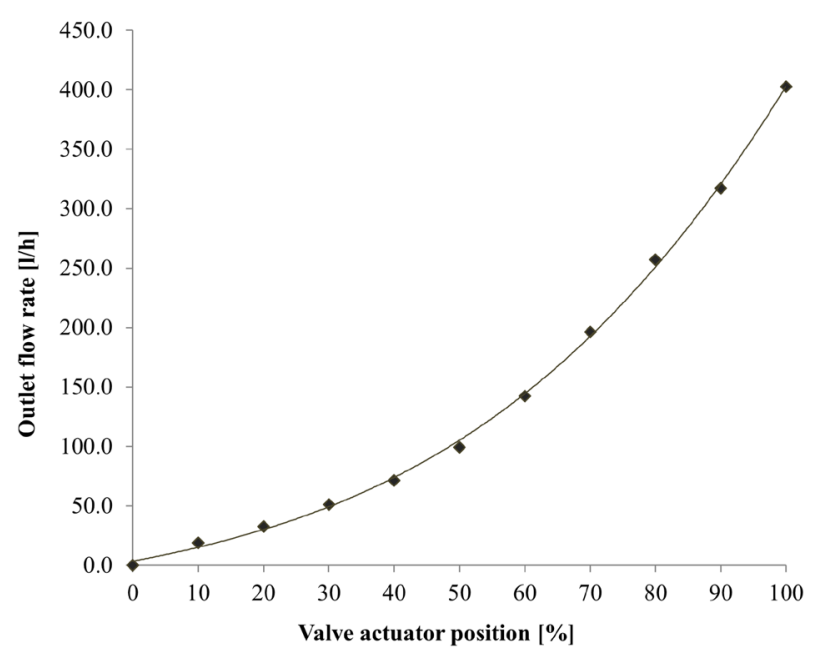

Fig. 2 Valve characteristic curve

Table 2 The flow measurement results at different operation points

\begin{tabular}{lccc}
\hline Operation point & 1 & 2 & 3 \\
\hline Setpoint of actuator position [\%] & 25 & 50 & 75 \\
Measured actuator position [\%] & 21.7 & 47.4 & 72.8 \\
Outlet flow rate [1/h] & 32.9 & 96.7 & 209.4 \\
Inlet velocity [m/s] & 0.0373 & 0.1095 & 0.2372 \\
Reynolds number & 578 & 1351 & 2578 \\
\hline
\end{tabular}

\subsection{Temperature measurements with Pt100} temperature probes

The intensity of the heating can be set between 0 and $100 \%$. In the first experiment we investigated the dynamic responses of the system by varying the heating intensity in steps. The actuator position of the control valve was set to $25 \%$. The setpoint of the heating was gradually increased from $0 \%$ to $100 \%$ by $25 \%$ steps, then it was gradually decreased to $0 \%$ by $25 \%$ steps. The inlet temperature, the heating intensity and the step responses of the outlet temperature are shown in Fig. 3.

The same step response analysis was performed at 50 and $75 \%$ valve opening (FV001), and the results are in Fig. 4. The measured steady-state outlet temperatures are higher in case of lower flow rates and higher heating setpoints. The steady-state temperature characteristics are linear, which is advantageous in solving various regulatory control tasks. The linearity of the system mainly

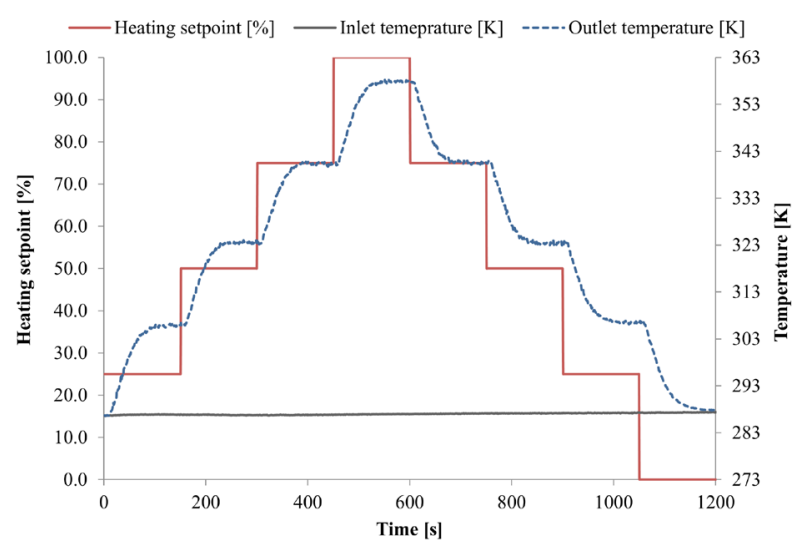

Fig. 3 The result of the heating experiment at $25 \%$ flow rate

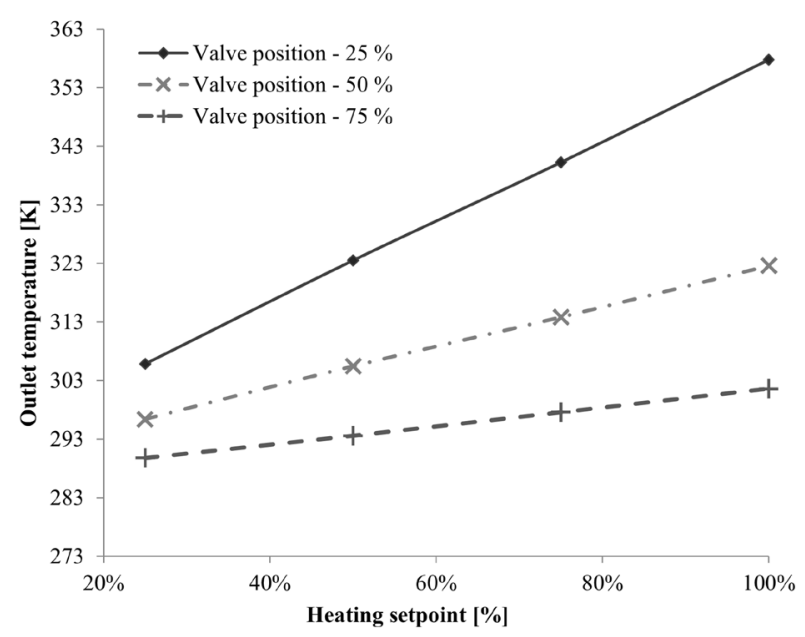

Fig. 4 Steady-state outlet temperatures at 25, 50 and $75 \%$ valve opening 
comes from the fact that the electric heating is efficient, and it does not decrease with the temperature.

\subsection{Measurement with infrared sensors}

The Pt100 sensors provide information about the outlet temperature of the flowing agent and it is sufficient for temperature control objectives. However, to understand the detailed heat transfer process over the entire length of the heat exchanger, more information is required. For this purpose, we used a FLIR A35sc infrared camera (5\% accuracy) to obtain surface temperatures of the heat exchanger. The FLIR commercial software was used for the calibration of the infrared camera, and the camera was attached to a data acquisition computer by Ethernet connection. The focal distance was set to $80 \mathrm{~cm}$, while the reflection temperature was set to $295 \mathrm{~K}$. In the experiment with the infrared camera, the steady-state outer surface temperatures of the heat exchanger tubes were measured at $50 \%$ and $100 \%$ heating intensity. The FLIR software makes it possible to define measurement points, so it becomes possible to follow the dynamic changes in the temperature on the surface. Besides that, the temperature of the warmest, the coldest points and the average temperature values were calculated. Fig. 5 shows an example of the infrared measurements with $25 \%$ opening of the control valve. Eight different surface points (Sp1-8) were defined along the length of the exchanger to record surface temperatures.

As Fig. 5 shows the surface temperature increases along the length of the tube. The maximum temperature was measured at a copper nut which is used to fix the pipes. The same temperature scale was applied in both cases.

a)

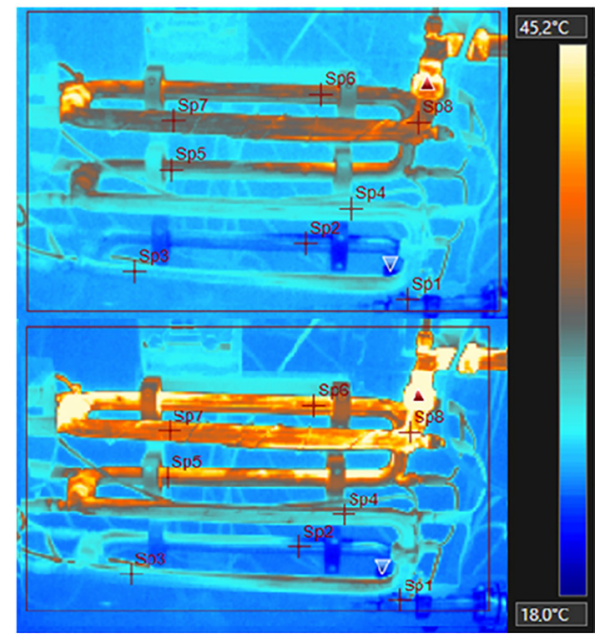

Fig. 5 Infrared temperature measurement of the system. a) steady-state values at $50 \%$ heating intensity; b) steady-state values at $100 \%$ heating intensity
For case Fig. 5 a) the temperature changes between 295 and $305 \mathrm{~K}$, and for case Fig. 5 b) the temperature changes between 297 and $316 \mathrm{~K}$. The maximum temperature is at the outlet in both cases.

\section{The CFD model of the heat exchanger}

The detailed model of the heat exchanger was implemented in COMSOL Multiphysics [22, 23]. The main steps of the model building are defining the governing equations, the material properties, and the boundary conditions. The crucial points after the parameter definitions are the mesh independence study (see Subsections 4.1.1 to 4.1.3) and the verification of the model (see Subsection 4.2).

The $k-\varepsilon$ turbulence model was used to calculate turbulent flow in the heat exchanger [24, 25]. In case of low Reynolds number a modification of the $k-\varepsilon$ turbulence model can be used, where the fluid velocities near the wall can be set to $0[26,27]$.

The enthalpy balance for the fluid phase can be formalised by the following simplified equations (Eqs. (2) and (3)) using the fluid phase temperature [22, 23].

$$
\begin{aligned}
& \rho c_{p}\left(\frac{\partial T}{\partial t}+(\boldsymbol{v} \times \nabla) T\right) \\
& =-(\nabla \boldsymbol{q})+\tau: \boldsymbol{S}-\left.\frac{T}{\rho} \frac{\partial \rho}{\partial T}\right|_{p}\left(\frac{\partial \rho}{\partial t}+(\boldsymbol{v} \times \nabla) p\right)+Q \\
& \tau=\boldsymbol{S}-\frac{1}{3 \rho}(\boldsymbol{v} \times \nabla) I \quad \boldsymbol{S}=\frac{1}{2}\left(\nabla \boldsymbol{v}+(\nabla \boldsymbol{v})^{T}\right)
\end{aligned}
$$

The conduction and the heat transfer terms are considered for the solid phase (Eq. (4)). The index $i$ refers to the solid material; the material properties were different for ceramic, steel and kanthal (heating wire material).

$\rho c_{p, i} \frac{\partial T}{\partial t}=\nabla \times\left(\lambda_{i} \nabla T_{i}\right)+Q$

There is one additional process which has to be considered, the electrical heating. The two endpoints of the heating wires are defined as voltage and ground. The heat transport can be described in the form of Eq. (3), but the source term should be implemented by Eqs. (5) and (6) [22, 23].

$Q=\nabla \boldsymbol{J}$

$J=-\sigma \nabla V$

In order to solve the flow equations, the material properties must be provided. The fluid phase in the system is water, and its properties are well known. Besides that, there are some solid materials (structural steel, ceramic, kanthal) whose properties must be known. The COMSOL 
built-in material library was used for the calculation of material properties in case of the temperature-dependent density, viscosity, heat capacity and thermal conductivity of water, and thermal properties of the steel and ceramic parts [22, 23]. Equations (7)-(10) were used in simulations to determine the temperature dependency of material properties of water.

$$
\begin{aligned}
& c_{p}^{w}(T)=3.6254 \times 10^{-7} T^{4}-5.3819 \times 10^{-4} T^{3}+0.3098 T^{2} \\
& -80.4073 T+12010.1471 \\
& \lambda^{w}(T)=7.9754 \times 10^{-9} T^{3}-1.5837 \times 10^{-5} T^{2} \\
& +8.9489 \times 10^{-3} T-0.8690 \\
& \rho^{w}(T)=3.7182 \times 10^{-7} T^{3}-3.0112 \times 10^{-3} T^{2}+1.4005 T \\
& +838.4661 \\
& \mu^{w}(T)=3.8457 \times 10^{-16} T^{6}-9.0790 \times 10^{-13} T^{5} \\
& +8.9043 \times 10^{-10} T^{4}-4.6454 \times 10^{-7} T^{3}+1.3605 \times 10^{-4} T^{2} \\
& -2.1224 \times 10^{-2} T+1.3799
\end{aligned}
$$

Equations (7) to (9) can be applied in a temperature range of 273.15-553.75 K, and Eq. (10) can be used from 273.15 to $413.15 \mathrm{~K}$. All measured and simulated values were within these ranges. For steel and ceramic parts constant values were used as $c_{p}^{s}=475 \mathrm{~J} /(\mathrm{kg} \mathrm{K}), \lambda^{s}=44.5 \mathrm{~W} /$ $(\mathrm{m} \mathrm{K})$ for steel and $c_{p}^{c}=703 \mathrm{~J} /(\mathrm{kg} \mathrm{K}), \lambda^{s}=1.38 \mathrm{~W} /(\mathrm{m} \mathrm{K})$ for ceramic parts. In case of the heating wire, which is made from kanthal alloy, the specification sheet issued by SANDVIK company was used to calculate the heat capacity and heat conductivity (Eqs. (11) and (12)). SANDVIK [28] provides heat capacity and heat conductivity values of kanthal alloys at some specific temperatures. Using these data, the following polynomial expressions were obtained by fitting a polynomial to the data, where the temperature is in $[\mathrm{K}]$.

$$
\begin{aligned}
& c_{p}^{K}(T)=3 \times 10^{-10} T^{3}-10^{-6} T^{2}+3 \times 10^{-3} T+0.1658 \\
& \lambda^{K}(T)=3 \times 10^{-6} T^{2}+9.6 \times 10^{-3} T+7.8842
\end{aligned}
$$

The density of the kanthal alloy was considered as a constant $7100 \mathrm{~kg} / \mathrm{m}^{3}$.

\subsection{Modelling and validation of the heat exchanger}

The full 3D model provides the most information about the system. However, solving a model with different length scales resulted in disturbances in the convergence, so a two-step model was proposed consisting of a $2 \mathrm{D}$ model for the heating wire and a $3 \mathrm{D}$ model for the rest. In the final version, the heating wire was implemented as a heat flux boundary condition, where the heat flux is derived from the $2 \mathrm{D}$ representation. The following sections provide the steps for the model building.

\subsubsection{Detailed 3D model}

The real geometry of the heat exchanger was implemented in COMSOL Multiphysics, as shown in Fig. 6. The physical system was implemented in 1:1 scale. The horizontal parts were extended with the concentric cylinders of the heating wires and ceramic insulation. The black arrows indicate the inlet and outlet of the water where the temperature probes are placed.

Fig. 6 shows that the main dimensions of the parts differ significantly in the three directions of space. For example, heating wire and its ceramic insulation is $350 \mathrm{~mm}$ long but its diameter only $6 \mathrm{~mm}$. This length difference causes difficulties during mesh generation because the minimal element size should be very small, especially near the smallsized boundaries. The cross-section of the heating tubes is shown in Fig. 7. The black circle represents the heating wire; the white part is ceramic; the grey is the steel cover and the blue part is the domain of the flowing water.

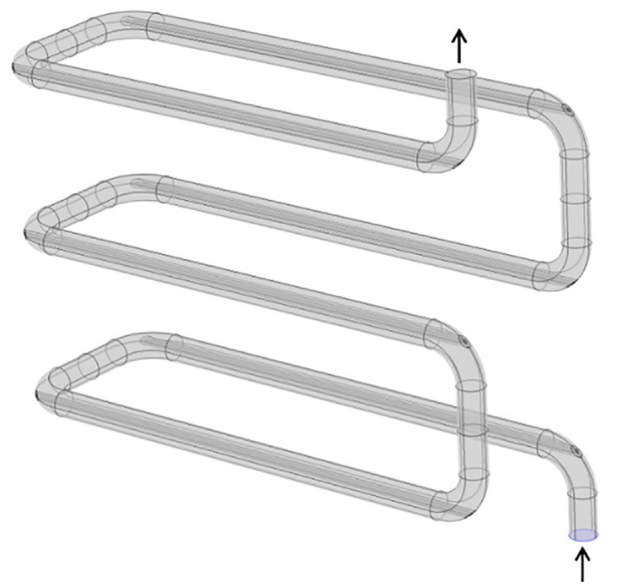

Fig. 6 The implemented realistic 3D geometry of heat exchanger

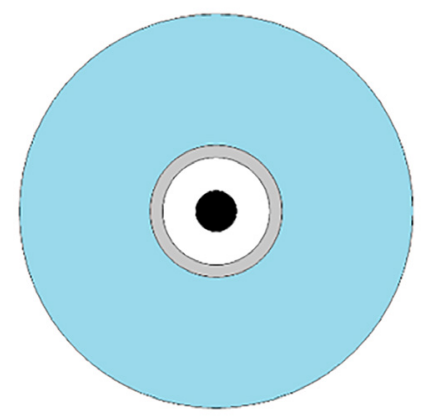

Fig. 7 A vertical section of the device 
The inlet boundary was defined as a fixed velocity inlet for each simulation, while the outlet was defined as a no-stress outlet boundary (with relative pressure calculation) $[22,23]$. The computational grid is unstructured with tetrahedral elements. Fig. 8 shows a small part of the calculation grid. The inner parts of the fluid domain contain bigger elements, while the solid layers contain smaller elements due to the small thickness. The mesh generation resulted in a large number of tetrahedral elements. For the solution of the model, a robust direct solver, the PARDISO was used [29].

For the numerical verification of the model a mesh independence study was performed at $50 \%$ opening of the control valve and $100 \%$ heating intensity, and the results are presented in Fig. 9.

The relative balance errors were referred to integrated values at the inlet boundary (Eqs. (13) and (14)).

$$
\begin{aligned}
& E_{\text {mass }}=\frac{\left(\int_{A} \rho|\boldsymbol{v}| \mathrm{d} A\right)_{\text {outlet }}-\left(\int_{A} \rho|\boldsymbol{v}| \mathrm{d} A\right)_{\text {inlet }}}{\left(\int_{A} \rho|\boldsymbol{v}| \mathrm{d} A\right)_{\text {inlet }}} \\
& E_{\text {enthalpy }}=\frac{\left(\int_{A} \rho c_{p}|\boldsymbol{v}| T \mathrm{~d} A\right)_{\text {outlet }}-\left(\int_{A} \rho c_{p}|\boldsymbol{v}| T \mathrm{~d} A\right)_{\text {inlet }}}{\left(\int_{A} \rho c_{p}|\boldsymbol{v}| T \mathrm{~d} A\right)_{\text {inlet }}}
\end{aligned}
$$

With the increasing number of the mesh elements the numeric solution does not converge to a specific value and the computational time also increases. Significant errors were encountered in case of the heat balance, which are probably originated from the calculation of the solid phase heat transport processes, where the calculation domain contains a large number of mesh element due to the substantial length differences and refinements at the contact surfaces. In order to solve the problem, a 2D axisymmetric model of the heating wires was implemented to calculate the heat flux across the whole device.
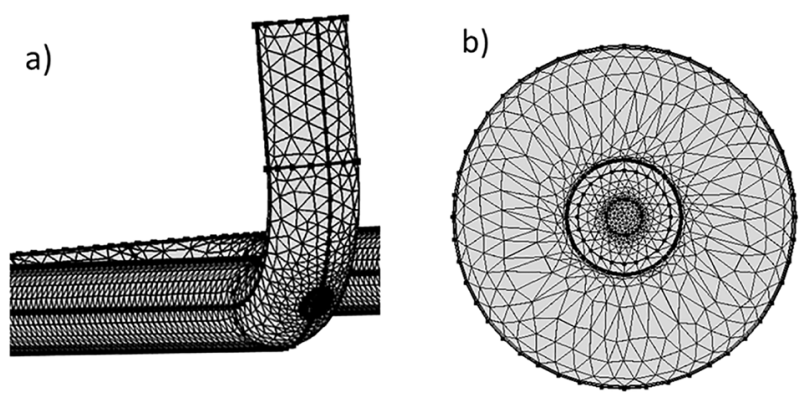

Fig. 8 a) A part of the calculation mesh of the realistic 3D model (1248k elements); and b) calculation mesh in the cross-section of the pipe

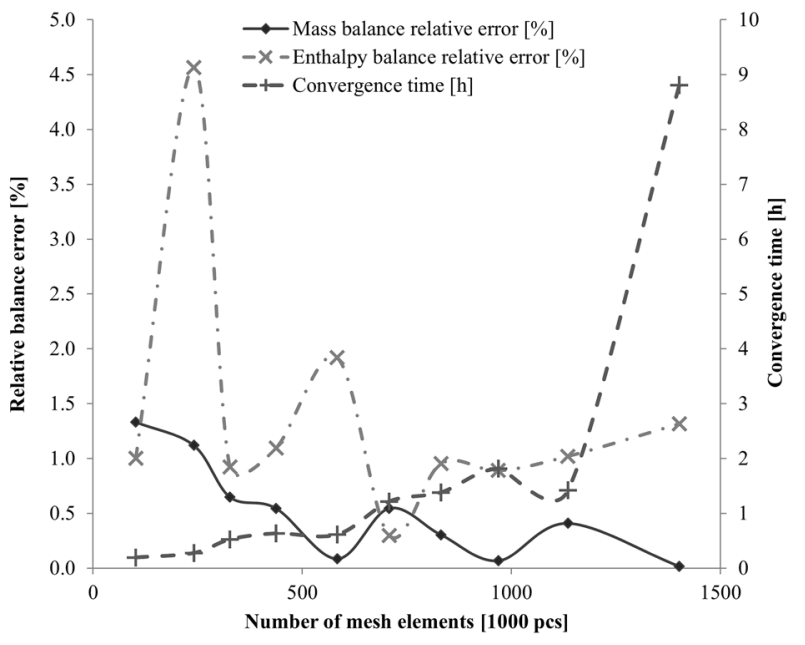

Fig. 9 Mesh independence study in case of the realistic model

\subsubsection{D axisymmetric model of the heating wire}

In case of symmetric geometry application, the computational requirements can be significantly reduced by using only a slice of the geometry instead of the whole 3D domain. The geometry of the heat exchanger was implemented as a long tube including only the six horizontal heating sections built after each other. The elbows and vertical segments were neglected in the calculations because they do not affect the enthalpy balance. With these simplifications, only four different rectangle-shaped domain using structured rectangular mesh must be calculated.

The same boundary conditions were applied as in the 3D simulation. The simulated outlet temperatures were compared to the measured temperatures at $50 \%$ opening of the flow control valve and $100 \%$ heating intensity. The simulated outlet temperature was $323 \mathrm{~K}$, while the measured was $322.7 \mathrm{~K}$, which is an excellent agreement. The transferred heat flux from the heating wire was $3654 \mathrm{~W} / \mathrm{m}^{2}$ (the nominal value is $4000 \mathrm{~W} / \mathrm{m}^{2}$ ). Since the relationship between the heating intensity and the outlet temperature is linear (see Fig. 4) the heat flux can be calculated at each heating intensity if the maximal value is the identified $3654 \mathrm{~W} / \mathrm{m}^{2}$.

\subsubsection{The reduced 3D model with information from the 2D model}

The 3D geometry can be simplified with information gained from the $2 \mathrm{D}$ simulations, so the heating wire can be replaced with a heat flux boundary condition. The information loss is negligible, and the mesh network is much smoother with an acceptably low computational time. The mesh independence study was performed using the PARDISO solver on the reduced 3D model, and the result is shown in Fig. 10. 


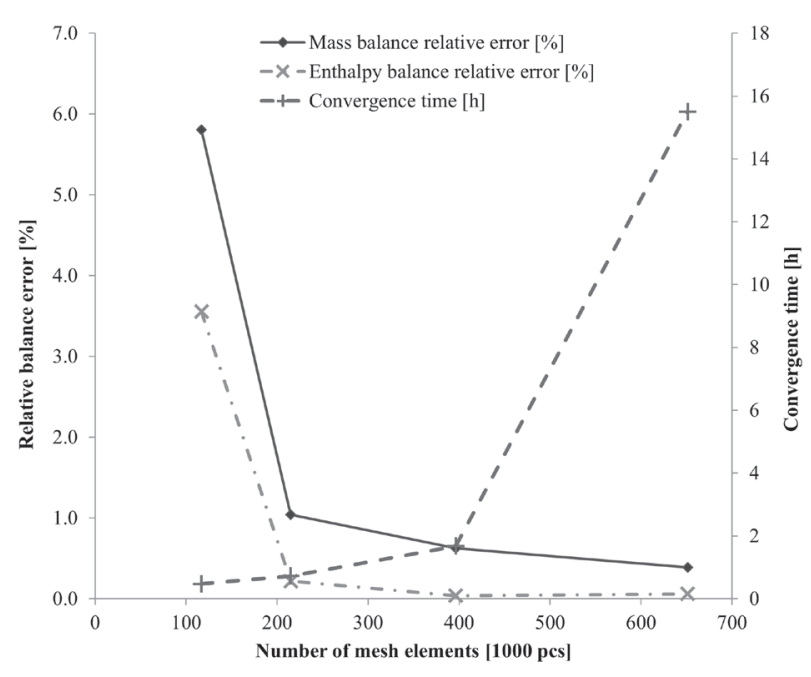

Fig. 10 Mesh independence study in case of the realistic model

Increasing the mesh elements result in a decrease of the model error, and the oscillation which happened in case of the realistic 3D model, was not experienced anymore. Based in Fig. 10 a computational grid containing 400000 mesh elements was selected for further investigations. Fig. 11 also confirms the choice of 400000 mesh elements from a different perspective, where the measured and simulated outlet temperatures can be seen in the function of the number of mesh elements. Increasing the number of mesh elements results in lower simulation error. In case of modelling a real heat exchanger system the mesh independence study should always be done, because the low relative balance error on its own does not mean that the simulation will result according to the measured values.

The reliability of the model was checked at different openings of the control valve and heating intensity, as it can be seen in Fig. 12. It can also be seen that the model is reliable at 50 and $75 \%$ opening of the control valve, but the

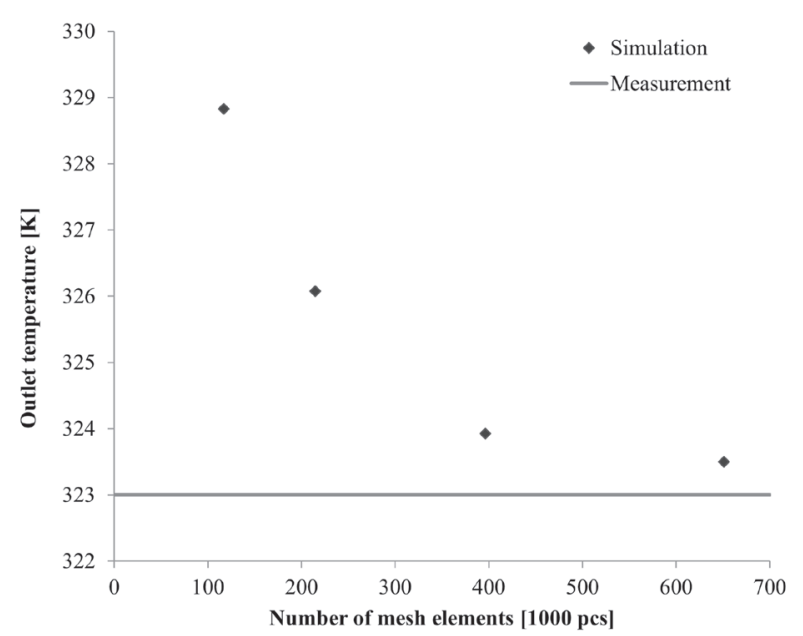

Fig. 11 Mesh independence study in case of the reduced model

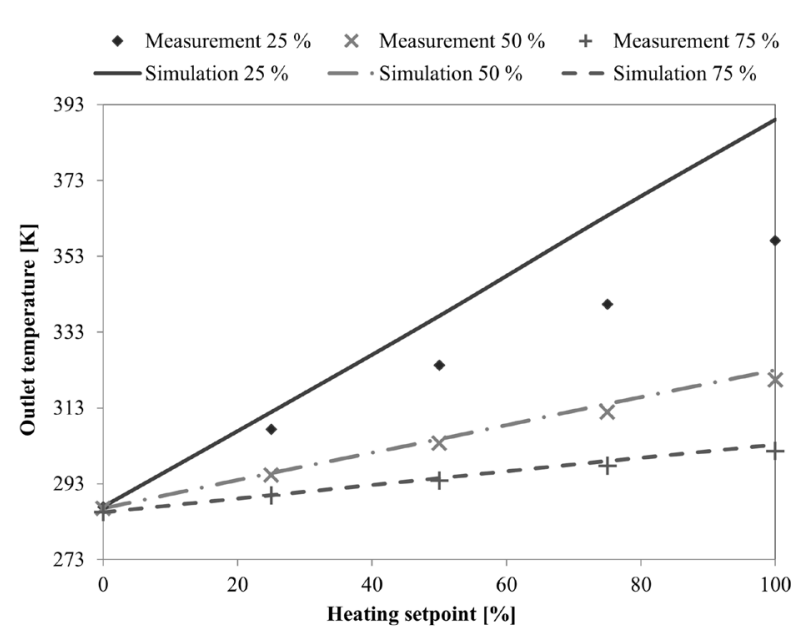

Fig. 12 Comparison of the measured and simulated temperatures

results are unacceptable at $25 \%$ opening, where the temperature difference between the simulated and measured at $100 \%$ heating intensity is higher than $310 \mathrm{~K}$. The error is due to the heat loss into the environment; hence we had to implement its effect into the model. We noticed that the impact of the heat loss is only significantly present in case of the $25 \%$ valve opening since the temperature, so the transferred heat is the highest (compared to other measurements) at this operating point. The exact values in Fig. 12 are introduced in Table 3.

The model which does not consider heat loss is not suitable for describing the exact heat transfer processes. To overcome this problem a heat flux boundary was defined at the outer surface of the heat exchanger, so we can model the heat transfer between the heat exchanger and the environment. For this purpose, the wall of the steel pipe was defined as a highly conductive layer. In this way, the heat conduction through the steel coating layer can be modelled without implementing its geometry [22, 23]. This type of boundary condition calculates the heat transport using the properties and the thickness of the layer. The heat conductivity of the steel was defined as $44.1 \mathrm{~W} /(\mathrm{m} \mathrm{K})$, and the thickness of the layer was set to $1.8 \mathrm{~mm}$ (derived from the physical system).

Table 3 Measured and simulated outlet temperature differences

\begin{tabular}{lcccccc} 
& \multicolumn{2}{c}{ Valve position: } & \multicolumn{2}{c}{ Valve position: } & \multicolumn{2}{c}{ Valve position: } \\
& \multicolumn{2}{c}{$25 \%$} & \multicolumn{2}{c}{$50 \%$} & \multicolumn{2}{c}{$75 \%$} \\
Heating & $T$ & Error & $T$ & Error & $T$ & Error \\
Intensity & {$[\mathrm{K}]$} & {$[\mathrm{K}]$} & {$[\mathrm{K}]$} & {$[\mathrm{K}]$} & {$[\mathrm{K}]$} & {$[\mathrm{K}]$} \\
\hline $0 \%$ & 286.9 & 0.8 & 286.5 & 0.03 & 285.5 & 0.07 \\
$25 \%$ & 313.3 & 6.0 & 295.6 & 0.35 & 289.7 & 0.25 \\
$50 \%$ & 340.1 & 15.8 & 304.8 & 1.10 & 293.9 & 0.05 \\
$75 \%$ & 367.1 & 26.7 & 314.0 & 2.12 & 298.1 & 0.37 \\
$100 \%$ & 394.3 & 37.2 & 323.3 & 2.93 & 302.4 & 0.77 \\
\hline
\end{tabular}


The solid-fluid heat transfer coefficient was identified by the measured surface temperatures calculating the squared error between the infrared measurements and the simulated surface temperatures. The overall heat transfer coefficient is $800 \mathrm{~W} /\left(\mathrm{m}^{2} \mathrm{~K}\right)$. Fig. 13 shows the result of the model with a heat loss calculation, where a significant improvement was reached at 25 and $50 \%$ opening of the control valve. As we can see in Fig. 13, we were able to develop a model which accurately meets the outlet temperature measurements, where the average relative error is $6.5 \%$. The overall accuracy of the measurement is $1 \%$, hence the simulation error may come from the 3D model reduction.

\subsection{Model validation with infrared temperature measurements}

CFD simulators ensure that the calculated values can be extracted from the entire computation domain. The additional information that can be obtained this way was used to validate our model based on the infrared camera measurements as well. The surface temperature values were derived at the specific points defined during the infrared measurements. Figs. 14 to 16 show the results of the comparison of the surface points in case of all three valve positions $(25 \%, 50 \%, 75 \%)$.

There are some differences between the measured and simulated values, mainly due to the uncertainty of the measurements. At the first measurement point, a relative error of $14-15 \%$ occurs, showing the uncertainty of the surface measurement point selection by graphic methods. At the other points, the relative error changes between in the range of $0 \%$ and $7 \%$, and the average relative error is $3-4 \%$. An error of $4 \%$ is considered acceptable for

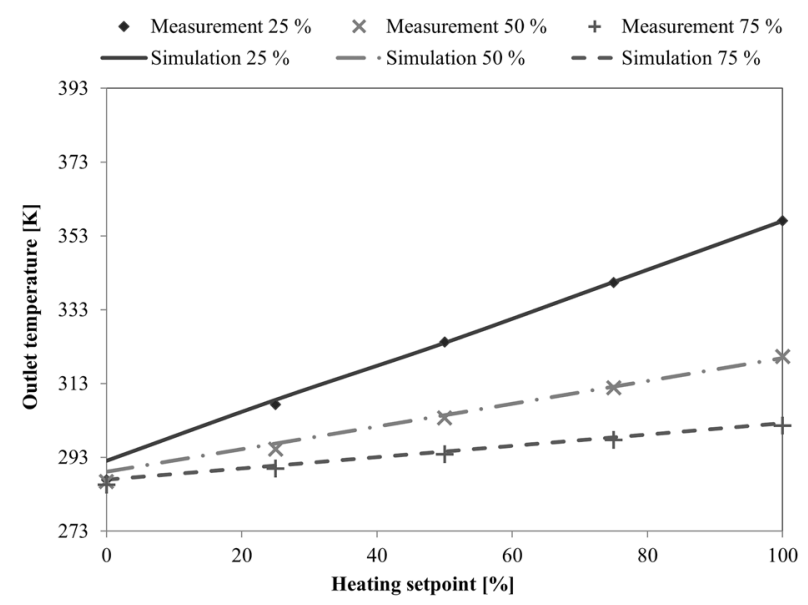

Fig. 13 Comparison of the measured and the simulated temperatures with heat loss calculation

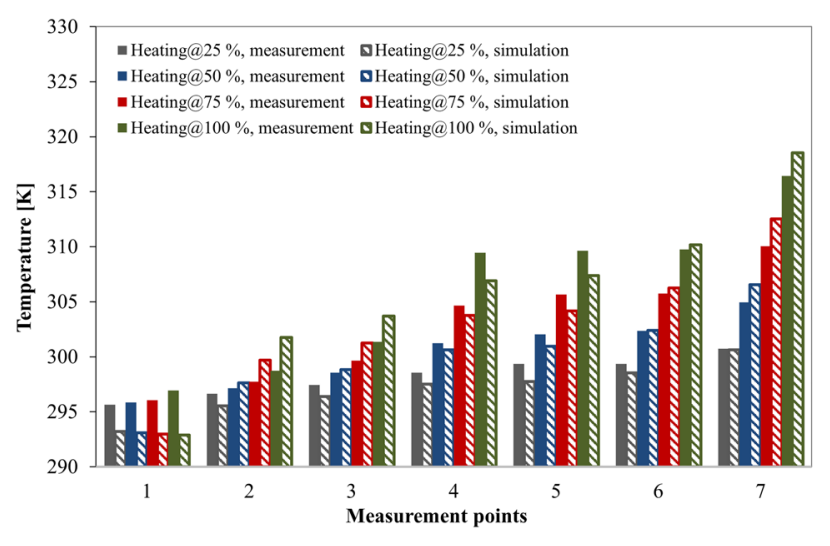

Fig. 14 Model validation based on the surface temperatures at $25 \%$ valve opening

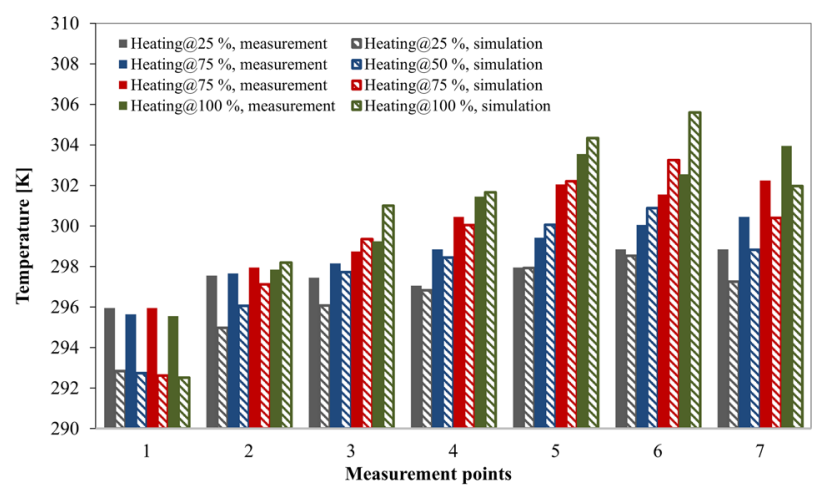

Fig. 15 Model validation based on the surface temperatures at $50 \%$ valve opening

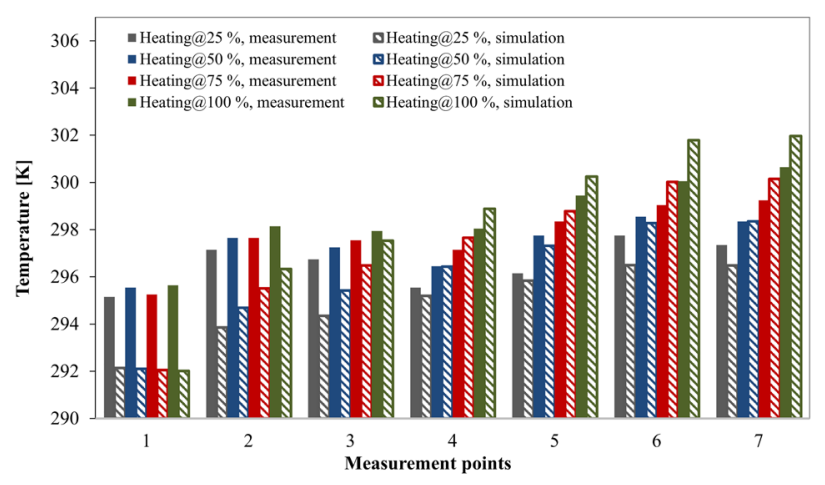

Fig. 16 Model validation based on the surface temperatures at $75 \%$ valve opening

similar cases in [30]. The overall accuracy of the measurement is $5.1 \%$. The rather small relative error indicates that the model can be considered valid.

The red triangles in Fig. 17 show the places where the simulation underestimates the temperatures, while the blue triangles indicate the areas where the simulation overestimates the temperatures. The same trend can be seen at $25 \%$ valve actuator position and $50 \%$ heating 
(Fig. 17 a), $50 \%$ valve actuator position and $100 \%$ heating (Fig. 17 b), and $75 \%$ valve actuator position $100 \%$ heating (Fig. 17 c). (All values in Fig. 17 are in ${ }^{\circ} \mathrm{C}$.)

The colour legends inserted in the figures do not show the same range for all simulation results and measurements so that these plots can only be used for qualitative evaluation. For quantitative assessment of results, the data derived from the surface measurement points can be used. On the surface of elbows, areas with higher temperatures are found. Similarly, inside the elbows, volumes with higher temperatures can be observed by the CFD simulations.

\section{Case studies}

We used the valid model for investigating different types of performance losses. In Subsection 5.1 we present performance losses related to the fouling phenomenon. In Subsection 5.2 we present how the failure of the heating wire affects the performance.

\subsection{Fouling related performance losses}

The heat exchanger fouling was modelled by the deposition of particles using the particle tracing module [22, 23]. The particle tracing simulation was set up as a flow-based particle tracing, and the particles were moving based on the drag and gravitational forces acting on each particle.

a)

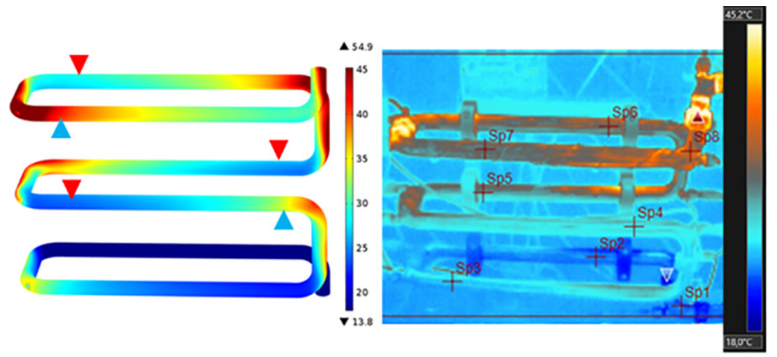

b)

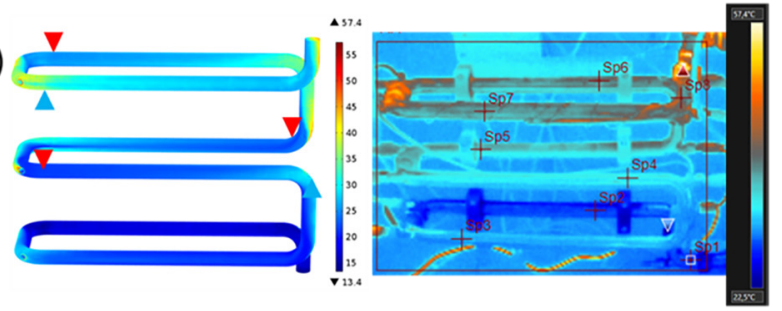

c)
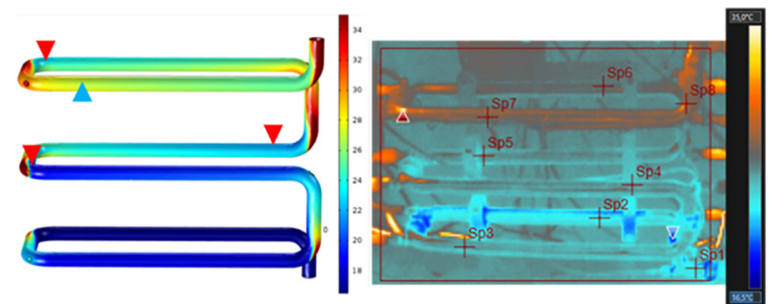

Fig. 17 a) Results with $25 \%$ valve position and $50 \%$ heating; b) Results with $50 \%$ valve position and $100 \%$ heating; c) Results with $75 \%$ valve position and $100 \%$ heating
The traced particles were followed in a transient simulation. The particles collided to some points of the walls and stayed there, which helps to identify the critical points of the heat exchanger. 250 particles were originated at the inlet boundary. Fig. 18 shows the result in the function of time. After $60 \mathrm{~s}$ most of the particles already left the heat exchanger, and the remaining particles marked the critical parts of the heat exchanger. After 60 s only the $93.6 \%$ of the particles left the heat exchanger. As it can be seen in Fig. 18, the deposition will most likely develop where the flow direction changes fast or where the flow is fractured. In these critical locations and next to the wall the velocity of the fluid is much lower, hence the probability of the deposition is higher. The heavier particles also cannot change their direction due to their greater inertia. In [31-33] the researchers found the same, so the lower velocities enhance the fouling.

Fig. 19 a) shows the deposited particles at $25 \%$ valve position, and Fig. 19 b) shows the deposited particles at $75 \%$ valve position at $t=60 \mathrm{~s}$. In case of $25 \%$ valve position the $15.2 \%$, while in the case of $75 \%$ valve position $21.6 \%$ of the particles were deposited.

Then the deposition phenomenon was modelled as regions with lower heat transfer coefficient. Fig. 20 shows the results at $25 \%$ valve position, and $100 \%$ heating intensity. $54 \%$ of heat transfer loss was predicted at the elbows based on the coverage of the particles. (All values in Fig. 20 are in ${ }^{\circ} \mathrm{C}$.)

The difference between the original case, and the deposited case is that the temperatures are higher at the

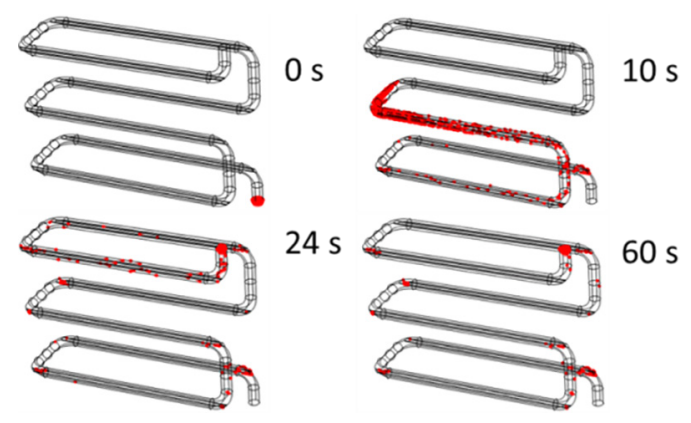

Fig. 18 Results of the particle tracing simulation a)

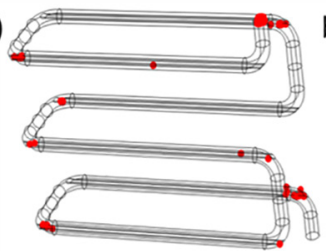

b)

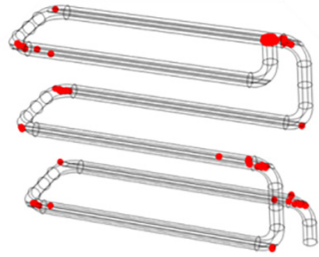

Fig. 19 Deposited particles at the end of the simulation with valve position: a) $25 \%$ valve opening; b) $75 \%$ valve opening 


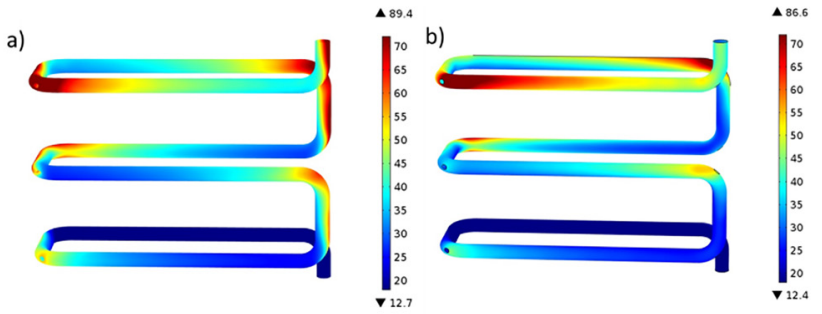

Fig. $2025 \%$ valve position, $100 \%$ heating intensity; a) original simulation results; b) results with particle deposition

elbows in case of the original simulation and lower near the heating wire. The outlet temperature decreased from $357 \mathrm{~K}$ to $351 \mathrm{~K}$ due to the deposits on the electrical wire.

\subsection{Heating wire failure related performance losses}

The heating wire failure is one of the most common causes of performance loss in electrical heat exchangers. The device contains six heating wires which boundary conditions can be set individually. The failure of the $3^{\text {rd }}$ heating wire was modelled, which results in a heat loss of $609 \mathrm{~W}$.

Fig. 21 a) shows the original results at $25 \%$ valve position and $100 \%$ heating intensity, while Fig. 21 b) shows the results in case of heating wire failure at $25 \%$ valve position and $100 \%$ heating intensity. (All values in Fig. 21 are in ${ }^{\circ} \mathrm{C}$.)

The temperature profile became flat near the failed heating wire and became more intensive after the fourth one. The outlet temperature decreased from $357 \mathrm{~K}$ to $349.5 \mathrm{~K}$. Similar trends can be seen in case of higher valve position and heating intensity, differences appear only in the size and the positions of the hot points.

\section{Conclusion}

We presented the modelling steps of a laboratory-scale heat exchanger. Due to the inadequacy of the full realistic $3 \mathrm{D}$ model, the heating wire and its insulation were modelled using a 2D axisymmetric model. The model was validated using not only the temperature probe but infrared camera measurements as well. The average relative error in case of modelling the outlet temperature is $6.5 \%$ and it is the highest at zero heating intensity. The measurement accuracy is quite high (temperature measurement $0.01 \%$,

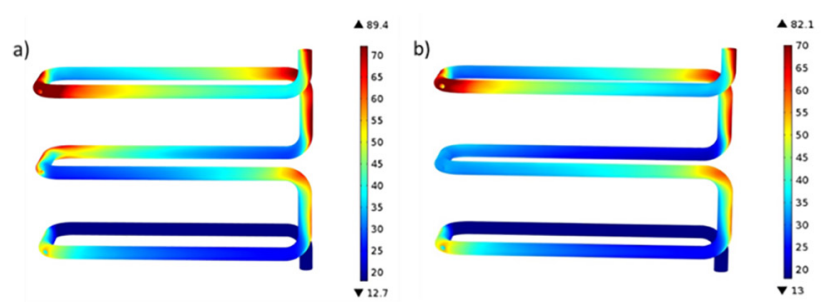

Fig. 21 Results at $25 \%$ valve position and $100 \%$ heating intensity; a) original simulation results; b) results with heating wire failure flow measurement $1 \%$ ), hence error may come from the fact that we used information from the 2D model in the $3 \mathrm{D}$ model, where the heating wire is replaced with a heat flux. In case of measuring the surface temperature the overall accuracy is $5.1 \%$, while the average relative error between the simulated and measured surface temperatures is $3-4 \%$. Errors may appear from the uncertainty of manual measurement point selection.

We showed how the developed CFD model of the equipment was used in different simulations and how it can be applied to investigate the performance losses due to failures of the heat exchanger. In this work we investigated two case studies. In the first case we modelled the fouling phenomenon using particle tracing module. We showed that the particles most likely deposit in that place, where the flow direction changes, or the flow is fractured. In the second case we investigated the performance loss due to the failure of an electrical heating wire. Based on the findings of this study, CFD simulations with validated models can be applied as a useful tool for the detailed design of heat exchangers which have risks of fouling or uses fluid streams with solid particles. If we know the highrisk places for deposition, we can reduce the chances of fouling or erosion caused by hard particles. Furthermore, conditions for an operating equipment can be predicted using a valid CFD model so the required maintenance can be scheduled without inspection or the replacement of the equipment can be forecasted too. Even certain risks which affect flow or heat characteristics, and their negative effects can be analyzed prior or during operation which will give information to the operating personnel how to react if any of these effects apply.

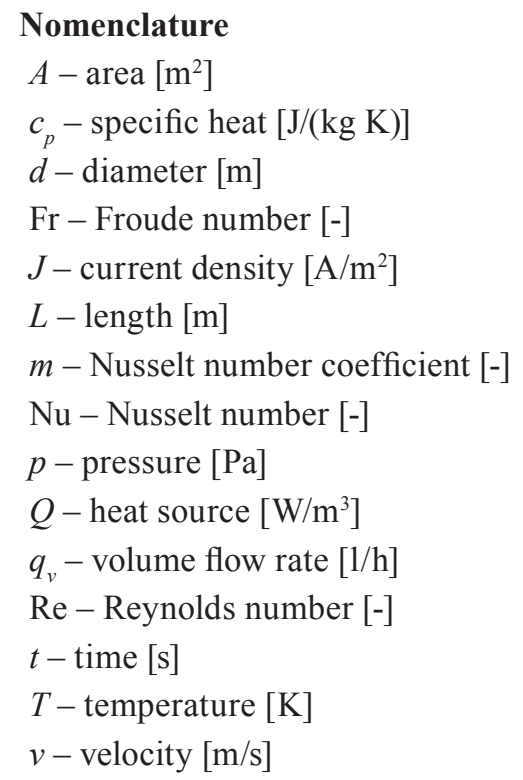


$V$ - volume $\left[\mathrm{m}^{3}\right]$

$x$ - Valve actuator positions [\%]

Greek letters

$\alpha$ - heat transfer coefficient $\left[\mathrm{W} /\left(\mathrm{m}^{2} \mathrm{~K}\right)\right]$

$\eta$ - dynamic viscosity [Pa s]

\section{References}

[1] Ocłoń, P., Łopata, S., Nowak, M., Benim, A. C. "Numerical study on the effect of inner tube fouling on the thermal performance of high-temperature fin-and-tube heat exchanger", Progress in Computational Fluid Dynamics, An International Journal, 15(5), pp. 290-306, 2015.

https://doi.org/10.1504/PCFD.2015.072014

[2] Han, Z., Xu, Z., Yu, X. "CFD modeling for prediction of particulate fouling of heat transfer surface in turbulent flow", International Journal of Heat and Mass Transfer, 144, Article number: 118428, 2019.

https://doi.org/10.1016/j.ijheatmasstransfer.2019.07.078

[3] Suárez, E., Paz, C., Porteiro, J., Eirís, A. "Simulation of the fouling layer evolution in heat transfer surfaces", In: V European Conference on Computational Fluid Dynamics, ECCOMAS CFD, Lisbon, Portugal, 2010, Article number: 8.

[4] Paz, C., Suárez, E., Conde, M., Vence, J. "Development of a Computational Fluid Dynamics Model for Predicting Fouling Process Using Dynamic Mesh Model", Heat Transfer Engineering, 41(2), pp. 199-207, 2020.

https://doi.org/10.1080/01457632.2018.1522108

[5] Lomax, H., Pulliam, T. H., Zingg, D. W. "Fundamentals of Computational Fluid Dynamics", Springer-Verlag, Heidelberg, Germany, 2001.

https://doi.org/10.1007/978-3-662-04654-8

[6] Patel, D. S., Parmar, R. R., Prajapati, V. M. "CFD Analysis of Shell and Tube Heat Exchangers - A review", International Research Journal of Engineering and Technology (IRJET), 02(09), pp. 2231-2235, 2015. [online] Available at: https://www.irjet.net/ archives/V2/i9/IRJET-V2I9261.pdf [Accessed: 03 March 2020]

[7] Ocłoń, P., Łopata, S. "Study of the Effect of Fin-and-Tube Heat Exchanger Fouling on its Structural Performance", Heat Transfer Engineering, 39(13-14), pp. 1139-1155, 2018. https://doi.org/10.1080/01457632.2017.1363619

[8] Ranade, V. V. "Computational flow modeling for chemical reactor engineering", Academic Press, San Diego, CL, USA, 2002.

[9] Ozden, E., Tari, I. "Shell side CFD analysis of a small shell-andtube heat exchanger", Energy Conversion and Management, 51(5), pp. 1004-1014, 2010. https://doi.org/10.1016/j.enconman.2009.12.003

[10] Aslam Bhutta, M. M., Hayat, N., Bashir, M. H., Khan, A. R., Ahmad, K. N., Khan, S. "CFD applications in various heat exchangers design: A review", Applied Thermal Engineering, 32, pp. 1-12, 2012.

https://doi.org/10.1016/j.applthermaleng.2011.09.001

[11] Rehman, U. U. "Heat Transfer Optimization of Shell-andTube Heat Exchanger through CFD Studies", Master's Thesis, Chalmers University of Technology, 2011. [online] Available at: https://publications.lib.chalmers.se/records/fulltext/155992.pdf [Accessed: 03 March 2020]

\author{
$\lambda$ - heat conductivity $[\mathrm{W} /(\mathrm{m} \mathrm{K})]$ \\ $\rho$ - density $\left[\mathrm{kg} / \mathrm{m}^{3}\right]$ \\ $\tau: S-$ stress tensor [-] \\ $\sigma-$ resistivity $[\mathrm{S} / \mathrm{m}]$
}

[12] Zeyninejad Movassag, S., Nemati Taher, F., Razmi, K., Tasouji Azar, R. "Tube bundle replacement for segmental and helical shell and tube heat exchangers: Performance comparison and fouling investigation on the shell side", Applied Thermal Engineering, 51(1-2), pp. 1162-1169, 2013.

https://doi.org/10.1016/j.applthermaleng.2012.10.025

[13] Han, H., He, Y. L., Tao, W. Q., Li, Y. S. "A parameter study of tube bundle heat exchangers for fouling rate reduction", International Journal of Heat and Mass Transfer, 72, pp. 210-221, 2014. https://doi.org/10.1016/j.ijheatmasstransfer.2014.01.010

[14] Pan, C., Zhang, T., Wang, J., Zhou, Y. "CFD study of heat transfer and pressure drop for oscillating flow in helical rectangular channel heat exchanger", International Journal of Thermal Sciences, 129, pp. 106-114, 2018. https://doi.org/10.1016/j.ijthermalsci.2018.02.035

[15] Youssef, W., Ge, Y. T., Tassou, S. A. "CFD modelling development and experimental validation of a phase change material (PCM) heat exchanger with spiral-wired tubes", Energy Conversion and Management, 157, pp. 498-510, 2018. https://doi.org/10.1016/j.enconman.2017.12.036

[16] Reddy, K. V. K., Kumar, B. S. P., Gugulothu, R., Anuja, K., Rao, P. V. "CFD Analysis of a Helically Coiled Tube in Tube Heat Exchanger", Materials Today: Proceedings, 4(2), pp. 2341-2349, 2017. https://doi.org/10.1016/j.matpr.2017.02.083

[17] Somasekhar, K., Malleswara Rao, K. N. D., Sankararao, V., Mohammed, R., Veerendra, M., Venkateswararao, T. "A CFD Investigation of Heat Transfer Enhancement of Shell and Tube Heat Exchanger Using $\mathrm{Al}_{2} \mathrm{O}_{3}$-Water Nanofluid", Materials Today: Proceedings, 5(1), pp. 1057-1062, 2018. https://doi.org/10.1016/j.matpr.2017.11.182

[18] Burlacu, A., Sosoia, G., Vizitiu, R. S., Bărbuță, M., Lăzărescu, C. D., Ciocan, V., Șerbănoiu, A. A. "Energy efficient heat pipe heat exchanger for waste heat recovery in buildings", Procedia Manufacturing, 22, pp. 714-721, 2018. https://doi.org/10.1016/j.promfg.2018.03.103

[19] Amanowicz, Ł. Wojtkowiak, J. "Validation of CFD model for simulation of multi-pipe earth-to-air heat exchangers (EAHEs) flow performance", Thermal Science and Engineering Progress, 5, pp. 44-49, 2018. https://doi.org/10.1016/j.tsep.2017.10.018

[20] Alfarawi, S., AL-Dadah, R., Mahmoud, S. "Transient investigation of mini-channel regenerative heat exchangers: Combined experimental and CFD approach", Applied Thermal Engineering, 125, pp. 346-358, 2017. https://doi.org/10.1016/j.applthermaleng.2017.07.038

[21] Ilori, O. M., Jaworski, A. J., Mao, X. "Experimental and numerical investigations of thermal characteristics of heat exchangers in oscillatory flow", Applied Thermal Engineering, 144, pp. 910-925, 2018. https://doi.org/10.1016/j.applthermaleng.2018.07.073 
[22] COMSOL "Introduction to COMSOL Multiphysics", [pdf] COMSOL, Available at: https://cdn.comsol.com/doc/5.5/ IntroductionToCOMSOLMultiphysics.pdf [Accessed: 10 December 2019]

[23] COMSOL "COMSOL CFD Module User's Guide", [pdf] COMSOL, Available at: https://doc.comsol.com/5.4/doc/com.comsol.help.cfd/ CFDModuleUsersGuide.pdf [Accessed: 10 December 2019]

[24] Wilcox, D. C. "Turbulence Modeling for CFD", DCW Industries, La Cañada, CA, USA, 2006.

[25] Larsson, J. "Numerical Simulation of Turbulent Flows for Turbine Blade Heat Transfer Applications", Doctoral Thesis, Chalmers University of Technology, 1998. [online] Available at: https://www. researchgate.net/profile/Jonas-Larsson-9/publication/34773501 Numerical_Simulation_Of_Turbulent_Flows_For_Turbine_Blade Heat_Transfer_Applications/links/5669393108ae7dc22ad3b8ab/ Numerical-Simulation-Of-Turbulent-Flows-For-Turbine-BladeHeat-Transfer-Applications.pdf [Accessed: 12 March 2020]

[26] Ignat, L., Pelletier, D., Ilinca, F. "A universal formulation of two-equation models for adaptive computation of turbulent flows", Computer Methods in Applied Mechanics and Engineering, 189(4), pp. 1119-1139, 2000. https://doi.org/10.1016/S0045-7825(99)00370-9

[27] Abe, K., Kondoh, T., Nagano, Y. "A new turbulence model for predicting fluid flow and heat transfer in separating and reattaching flows-I. Flow field calculations", International Journal of Heat and Mass Transfer, 37(1), pp. 139-151, 1994.

https://doi.org/10.1016/0017-9310(94)90168-6

\section{Appendix A: A summary of the temperature measurements}

Table 4 Measured temperatures on the inlet, outlet and on the surface at the first operating point

\begin{tabular}{|c|c|c|c|c|}
\hline Temperatures [K] & \multicolumn{4}{|c|}{ 1. operating point } \\
\hline $\begin{array}{l}\text { Actuator position of } \\
\text { control valve }\end{array}$ & \multicolumn{4}{|c|}{$25 \%$} \\
\hline Inlet temperature & \multicolumn{4}{|c|}{287.75} \\
\hline Heating Intensity & $25 \%$ & $50 \%$ & $75 \%$ & $100 \%$ \\
\hline $\begin{array}{l}\text { Maximum surface } \\
\text { temperature }\end{array}$ & 307.25 & 321.25 & 334.75 & 349.65 \\
\hline $\begin{array}{l}\text { Minimum surface } \\
\text { temperature }\end{array}$ & 292.55 & 292.45 & 292.35 & 292.85 \\
\hline $\begin{array}{l}\text { Average surface } \\
\text { temperature }\end{array}$ & 297.65 & 298.75 & 300.05 & 301.85 \\
\hline SP2 & 295.65 & 295.85 & 296.05 & 296.95 \\
\hline SP3 & 296.65 & 297.15 & 297.75 & 298.75 \\
\hline SP4 & 297.45 & 298.55 & 299.65 & 301.35 \\
\hline SP5 & 298.55 & 301.25 & 304.65 & 309.45 \\
\hline SP6 & 299.35 & 302.05 & 305.65 & 309.65 \\
\hline SP7 & 299.35 & 302.35 & 305.75 & 309.75 \\
\hline SP8 & 300.75 & 304.95 & 310.05 & 316.45 \\
\hline Outlet temperature & 307.36 & 324.28 & 340.36 & 357.13 \\
\hline
\end{tabular}

[28] SANDVIK "Kanthal ${ }^{\circledR}$ A-1", [online] Available at: https://www. kanthal.com/en/products/material-datasheets/strip/kanthal-a-1/ [Accessed: 02 March 2020]

[29] Sinnott, R. K. "Coulson \& Richardson's Chemical Engineering: Volume 6: Chemical Engineering Design", ButterworthHeinemann, Oxford, UK, 2005.

[30] Łopata, S. Ocłoń, P. "Numerical study of the effect of fouling on local heat transfer conditions in a high-temperature fin-and-tube heat exchanger", Energy, 92(1), pp. 100-116, 2015. https://doi.org/10.1016/j.energy.2015.03.048

[31] Andritsos, N., Karabelas, A. J. "Calcium carbonate scaling in a plate heat exchanger in the presence of particles", International Journal of Heat and Mass Transfer, 46(24), pp. 4613-4627, 2003. https://doi.org/10.1016/S0017-9310(03)00308-9

[32] Emani, S., Ramasamy, M., Shaari, K. Z. K. "Discrete phase-CFD simulations of asphaltenes particles deposition from crude oil in shell and tube heat exchangers", Applied Thermal Engineering, 149, pp. 105-118, 2019. https://doi.org/10.1016/j.applthermaleng.2018.12.008

[33] Kazi, S. N. "Fouling and Fouling Mitigation on Heat Exchanger Surfaces", In: Mirtovic, J. (ed.) Heat Exchangers - Basics Design Applications, IntechOpen Limited, London, UK, 2012, pp. 508-532. https://doi.org/10.5772/32990

Table 5 Measured temperatures on the inlet, outlet and on the surface at the second operating point

\begin{tabular}{|c|c|c|c|c|}
\hline Temperatures [K] & \multicolumn{4}{|c|}{ 2. operating point } \\
\hline $\begin{array}{l}\text { Actuator position of } \\
\text { control valve }\end{array}$ & \multicolumn{4}{|c|}{$50 \%$} \\
\hline Inlet temperature & \multicolumn{4}{|c|}{286.55} \\
\hline Heating Intensity & $25 \%$ & $50 \%$ & $75 \%$ & $100 \%$ \\
\hline $\begin{array}{l}\text { Maximum surface } \\
\text { temperature }\end{array}$ & 309.25 & 310.25 & 310.55 & 316.55 \\
\hline $\begin{array}{l}\text { Minimum surface } \\
\text { temperature }\end{array}$ & 292.05 & 292.15 & 292.15 & 291.65 \\
\hline $\begin{array}{l}\text { Average surface } \\
\text { temperature }\end{array}$ & 297.85 & 298.45 & 299.05 & 299.05 \\
\hline SP2 & 295.95 & 295.65 & 295.95 & 295.55 \\
\hline SP3 & 297.55 & 297.65 & 297.95 & 297.85 \\
\hline SP4 & 297.45 & 298.15 & 298.75 & 299.25 \\
\hline SP5 & 297.05 & 298.85 & 300.45 & 301.45 \\
\hline SP6 & 297.95 & 299.42 & 302.05 & 303.55 \\
\hline SP7 & 298.85 & 300.05 & 301.55 & 302.55 \\
\hline SP8 & 298.85 & 300.45 & 302.25 & 303.95 \\
\hline Outlet temperature & 295.27 & 303.70 & 311.90 & 320.37 \\
\hline
\end{tabular}


Table 6 Measured temperatures on the inlet, outlet and on the surface at the third operating point

\begin{tabular}{lcccc}
\hline Temperatures [K] & \multicolumn{4}{c}{ 3. operating point } \\
\hline $\begin{array}{l}\text { Actuator position of } \\
\text { control valve }\end{array}$ & \multicolumn{4}{c}{$75 \%$} \\
Inlet temperature & \multicolumn{4}{c}{285.55} \\
Heating Intensity & $25 \%$ & $50 \%$ & $75 \%$ & $75 \%$ \\
Maximum surface & 307.05 & 307.45 & 307.95 & 311.65 \\
temperature & & & & \\
Minimum surface & 290.95 & 291.55 & 291.75 & 291.35 \\
temperature & & & & \\
Average surface & 297.05 & 297.65 & 297.85 & 298.35 \\
temperature & & & \\
SP2 & 295.15 & 295.55 & 295.25 & 295.65 \\
SP3 & 297.15 & 297.65 & 297.65 & 298.15 \\
SP4 & 296.75 & 297.25 & 297.55 & 297.95 \\
SP5 & 295.55 & 296.45 & 297.15 & 298.05 \\
SP6 & 296.15 & 297.75 & 298.35 & 299.45 \\
SP7 & 297.75 & 298.55 & 299.05 & 300.05 \\
SP8 & 297.35 & 298.35 & 299.25 & 300.65 \\
Outlet temperature & 289.95 & 293.86 & 297.75 & 301.58 \\
\hline
\end{tabular}

